\title{
Introduction: Canada, Latin America, and International Health
}

\author{
Anne-Emanuelle Birn, MA, ScD
}

$\mathrm{I}$ $\mathrm{n}$ recent years, Canadian policy-makers, advocates, and researchers have paid increasing attention to the country's role in international health, motivated variously by principles of political pride, multilateral responsibility, diplomatic influence, biosecurity, economic selfinterest, and human rights. This effort to raise Canada's profile, rhetorically and through new research initiatives (though not necessarily increased foreign aid) has stimulated questions about the range and mode of health cooperation Canada expects to fulfill.

Canadians have also been proponents of international health's reconceptualization as "global health," as a means to understand - and redress - health and disease patterns in terms of the interplay of global, national, and local forces in political, economic, social, and scientific domains. Ultimately, global health is meant to transcend past ideological uses of international health - as a "handmaiden" of colonialism or a pawn of Cold War rivalries in underdeveloped countries - to suggest a shared global susceptibility to, experience of, and responsibility for health.

Although these developments imply a process of deep reflection, there has been little systematic analysis of Canada's involvement in international health historically, and the relevance of developing country approaches to the "new" global health remains under-examined. This special insert to the Canadian Journal of Public Health aims to fill these gaps from the vantage point of Canadian-Latin American interactions.

Latin America's longer perspective on the perils and possibilities of international health makes it a useful interlocutor: most of the region became involved in international health activities and institutions decades before Canada - through $19^{\text {th }}$ century sanitary treaties, participation in Panamerican health movements and organizations, and country-to-country exchanges to control epidemics.

Of course, Latin America is an enormously diverse region and encompasses an array of experiences in the international health arena, from the long-time neocolonial dependency of Central America on US (United States) public health intervention, to Southern South America's closer ties to socially-oriented French approaches, to larger settings of Mexico and Brazil playing various international and domestic influences against one another. Drawing upon European, North American, and Soviet practices, Latin America has, in turn, established its own models: Uruguay purveyed an influential social rights approach to child health starting in the 1920s; Cuba began providing South-South health cooperation in the 1960s; and in the 1980s, Nicaragua and Costa Rica became exemplars of primary health care's successful implementation.

Canada sponsored health-related missionary work circa 1900 and was represented in the League of Nations Health Organization in the 1920s, but it did not emerge as an independent international health player until the late 1940s, when Canadian psychiatrist Brock Chisholm became the World Health Organization's first Director-General. His efforts to infuse social medicine ideas into the agency were soon displaced by technically-oriented, 'vertical' disease campaigns employing the new tools of antibiotics and DDT. Canadian international health efforts in subsequent decades were largely characterized by a "follow the leader" approach in multilateral agencies and in Commonwealth-framed bilateral aid.

As Dmitrienko and Birn show, Canada only became involved in international health in Latin America in the 1970s and remains overshadowed by American activity. Usually treading carefully around "Monroe Doctrinism in health," the Canadian government has at times challenged US hegemony, tendering public health aid to Cuba and Nicaragua following their revolutions, and sponsoring a pivotal 1991 conference in Quebec on "International Health: A North South Debate."

Canadian involvement in Latin America has also generated innovative forms of cooperation, most notably through the International Development Research Centre (IDRC), which has championed collaborative "research for development." As Cole, Crissman, and Fadya Orozco demonstrate, the ideas of researchers and community activists in Ecuador, Brazil, and Paraguay have helped IDRC develop its "Eco-health" understanding of the interplay of social, political, economic, environmental, and cultural factors in shaping health and health research. IDRC has garnered world renown - though insufficient Canadian government funding - for fostering a

Canada Research Chair in International Health, University of Toronto, Toronto, ON. Guest editor of this special insert to the CJPH.

mutual agenda-setting process that contests the usual balance of power in international research patronage.

Notwithstanding the dominance of a unidirectional model of international health, whereby knowledge and projects are believed to diffuse from developed to developing countries, Latin America offers countless counter-examples of new ideas implemented locally, with potential to circulate to other settings and influence the international health arena. Here we explore two. Cohen's analysis of Brazil's decades-long defiance of US and international patent protection regimes in order to manufacture essential medicines to meet domestic priorities (most notably for anti-retrovirals) reveals useful lessons for Canadian and other health and human rights activists regarding the importance of chutzpah, long-term persistence, and creative legal strategies to protect social institutions from international imperatives.

In their account of Venezuela's "Barrio Adentro" program, Muntaner, Guerra Salazar, Rueda, and Armada trace how activist-residents of the poorest sections of Caracas - fed up with poor access to health care and neoliberal attempts at health system privatization - have designed and organized an international health effort with the aid of Cuban doctors who are housed and fed by local communities. This experience might lead Canadian researchers and advocates to imagine a new form of global health in which the principles of health cooperation are inverted to address local needs rather than donor priorities.

These papers were originally prepared for a workshop entitled "Latin American Perspectives on International Health," held at the University of Toronto in May 2005 and generously supported by Social Sciences and Humanities Research Council of Canada (SSHRC), Associated Medical Services, Inc., the Connaught Fund, and the Lupina Foundation. Other workshop papers appear in multilingual, open access issues of the Brazilian journal História, Ciências, Saúde Manguinhos 2006, 13(3) (available at www.scielo.br/hcsm) and the Canadian Bulletin of Medical History (www.cbmh.ca/, forthcoming 2007). We are most grateful to SSHRC and to the Canadian Institutes of Health Research-Institute of Population and Public Health - part of the Global Health Research Initiative - for funding this special CJPH insert.

We hope you agree that the papers published here offer fruitful avenues for exploring and understanding the evolving field of global health in Canada and Latin America - and will stimulate further research and debate on Canada's role in global health, past and present. 